\title{
Effect of calcium fluoride on the activity of dentin matrix-bound enzymes
}

\section{Altinci, Pinar}

2018-12

Altinci , P , Mutluay , M , Tjäderhane , L \& Tezvergil-Mutluay , A 2018 , ' Effect of calcium fluoride on the activity of dentin matrix-bound enzymes ' , Archives of Oral Biology , vol. 96 , pp. 162-168 . https://doi.org/10.1016/j.archoralbio.2018.09.006

http://hdl.handle.net/10138/307704

https://doi.org/10.1016/j.archoralbio.2018.09.006

publishedVersion

Downloaded from Helda, University of Helsinki institutional repository.

This is an electronic reprint of the original article.

This reprint may differ from the original in pagination and typographic detail.

Please cite the original version. 


\title{
Effect of calcium fluoride on the activity of dentin matrix-bound enzymes
}

\author{
Pinar Altinci $^{\mathrm{a}, \mathrm{b}, *}$, Murat Mutluay ${ }^{\mathrm{b}, \mathrm{c}}$, Leo Tjäderhane ${ }^{\mathrm{d}, \mathrm{e}}$, Arzu Tezvergil-Mutluay ${ }^{\mathrm{b}, \mathrm{c}}$ \\ ${ }^{a}$ Finnish Doctoral Program in Oral Sciences, Turku, Finland \\ ${ }^{\mathbf{b}}$ Department of Restorative Dentistry and Cariology, Institute of Dentistry, University of Turku, Turku, Finland \\ ${ }^{\mathrm{c}}$ Turku University Hospital, TYKS, University of Turku, Finland \\ d Department of Oral and Maxillofacial Diseases, University of Helsinki, Helsinki University Hospital, Helsinki, Finland \\ ${ }^{\mathrm{e}}$ Institute of Dentistry, University of Oulu, Medical Research Center Oulu, Oulu University Hospital, University of Oulu, Oulu, Finland
}

\section{A R T I C L E I N F O}

\section{Keywords:}

Dentin matrix

$\mathrm{CaF}_{2}$

Collagen degradation

Cysteine cathepsins

MMPs

\begin{abstract}
A B S T R A C T
Objective: Matrix metalloproteinases (MMPs) and cysteine cathepsins (CCs) are two distinct enzymatic pathways responsible for the degradation of collagen fibrils in demineralized dentin. $\mathrm{NaF}$ and $\mathrm{KF}$ have been shown to inhibit salivary MMP-2, -9 and CCs. This study investigated the inhibitory effect of calcium fluoride $\left(\mathrm{CaF}_{2}\right)$ on the dentin matrix-bound MMPs and CCs.

Design: Phosphoric acid (10\%)-demineralized dentin beams $(1 \times 2 \times 6 \mathrm{~mm})$ were incubated at $37^{\circ} \mathrm{C}$ in an $1 \mathrm{ml}$ of

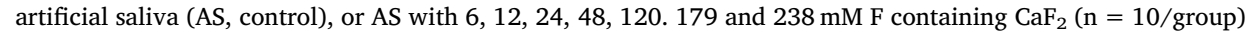
for 1, 7 and 21 days. All groups were further incubated in AS only for 6 months. Total MMP activity, dry mass loss, CTX and hydroxyproline (HYP) analyses were performed after each incubation. The beams were examined under scanning electron microscopy (SEM). MMP-2 and MMP-9 activities were screened with gelatin zymography. Data were analyzed by using ANOVA and Tukey HSD tests $(\mathrm{p}=.05)$.

Results: The total MMP activity was similar for all groups after 21 days and 6 months. After 21 days, the cumulative mass loss and CTX levels were lower compared to control for the $\mathrm{CaF}_{2} \geq 48$ and $\mathrm{CaF}_{2} \geq 120 \mathrm{mM}$, respectively $(\mathrm{p}<.05$ ). After 6 months, no significant difference was detected in the dry mass loss and CTX compared to the control ( $\mathrm{p}>.05$ ), whereas HYP level was higher with $\mathrm{F} 24$ and $238 \mathrm{mM}_{\text {groups. }} \mathrm{CaF}_{2}$-like minerals were observed on the beams under SEM. There was no gelatinase inhibition in zymography.

Conclusion: $\mathrm{CaF}_{2}$ does not prevent the degradation of demineralized dentin matrices due to the catalytic activity of MMPs and CCs.
\end{abstract}

\section{Introduction}

Auto-degradation of demineralized dentin organic matrix occurs by the catalytic activity of the endogenous dentin enzymes including mainly matrix metalloproteinases (MMP)-2, -8, -9 and cysteine cathepsin (CC)-K (Chaussain et al., 2013; Chaussain-Miller, Fioretti, Goldberg, \& Menashi, 2006; Frassetto et al., 2016; Mazzoni et al., 2015; Tjäderhane et al., 1998; Tjäderhane, 2015; Tjäderhane, Buzalaf, Carrilho, \& Chaussain, 2015). It is thought that these enzymes physiologically function during the teeth development phase, and fossilized in dentin with the maturation of teeth (Chaussain-Miller et al., 2006). Many studies showed that, due to the demineralization of dentin during cariogenic and erosive processes as well as adhesive bonding procedures requiring the use of acid-etchant or acidic resin monomers, these enzymes become re-activated, and cut off the type I collagen fibrils constituting dentin organic matrix (Buzalaf, Charone, \& Tjäderhane,
2015; Chaussain-Miller et al., 2006; Mazzoni et al., 2015; Tjäderhane et al., 2013a). As a consequence, remineralization cannot take place in these demineralized zones, leading to progressive dentin tissue loss (Tjäderhane et al., 1998). At the adhesive interfaces, these enzymatic activities together with the hydrolysis of resin components cause the premature failure of bonded restorations due to microleakage and secondary caries (Buzalaf et al., 2015; Tjäderhane et al., 2013a; Tjäderhane, 2015). Inhibition of dentin matrix-bound MMPs and CCs may hinder the progression of early carious and erosive lesions, and can enhance the clinical longevity of adhesive restorations by improving the hydrolytic stability of adhesive interfaces (Mazzoni et al., 2015; Tjäderhane et al., 2013a, 2013b; Tjäderhane, 2015; Tjäderhane et al., 2015).

Fluoride (F) is an antimicrobial anion improving the tooth demineralization resistance by forming less soluble fluorhydroxyapatite and fluorapatite minerals by interacting with the $\mathrm{Ca}^{2+}$ of enamel and dentin

\footnotetext{
* Corresponding author at: Department of Restorative Dentistry and Cariology, Institute of Dentistry, University of Turku, Lemminkaisenkatu 2, 20520, Turku, Finland.

E-mail address: pinaalt@utu.fi (P. Altinci).
} 
(ten Cate, 2013). Fluoridated anti-demineralization agents create $\mathrm{CaF}_{2}$ or $\mathrm{CaF}_{2}$-like crystals on teeth surfaces, so-called $\mathrm{F}$ reservoirs, releasing $\mathrm{F}$ ions to the environment under acidic challenges (Buzalaf, Pessan, Honório, \& ten Cate, 2011; Lussi, Hellwig, \& Klimek, 2012; Ogaard, 2001). During demineralization, the released $F$ ions intervene to the cariogenic process, and promote remineralization. Owing to these benefits, $\mathrm{CaF}_{2}$ has been experimentally incorporated into the composite resins in order to formulate F-releasing and antimicrobially effective restorative materials to prevent secondary caries (Xu, Moreau, Sun, \& Chow, 2010, 2010b; Cheng et al., 2012; Weir et al., 2012).

Recent studies have shown that F ions can inhibit the catalytic activity of salivary MMPs (Kato et al., 2014) as well as dentin matrixbound CCs (Altinci et al., 2016). Moreover, NaF and KF demonstrated quite similar inhibitory effect on CCs (Altinci et al., 2016; Altinci, Mutluay, Tjäderhane, \& Tezvergil-Mutluay, 2017). Hence, this study aimed to investigate if $\mathrm{CaF}_{2}$ has anti-enzymatic effect on the dentin matrix-bound MMPs and CCs, preventing the degradation of demineralized dentin matrices. The tested null hypothesis was $\mathrm{CaF}_{2}$ does not prevent the proteolytic degradation of demineralized dentin matrices due to the dentin matrix-bound MMPs and CCs.

\section{Materials and methods}

Fifty sound human molars stored in $0.02 \% \mathrm{NaN}_{3}$ disinfectant solution were used for the study series according to the approval of Ethical Committee, Faculty of Medicine, University of Oulu (\#19/2006). Two horizontal sections were done from the mid-coronal portions of the teeth to obtain dentin disks using a low-speed diamond saw (Isomet saw, Buehler Ltd., Lake Bluff, IL, USA) under continuous water-cooling. The disks were further sectioned into dentin beams $(1 \mathrm{~mm} \times 2 \mathrm{~mm} \times$ $6 \mathrm{~mm}$ ). The beams were demineralized in $10 \%$ phosphoric acid for $24 \mathrm{~h}$, rinsed in distilled water under constant stirring at $4{ }^{\circ} \mathrm{C}$ for $8 \mathrm{~h}$, and dried to a constant weight in a vacuum desiccator containing dry silica beads. After measuring the dry masses with a digital microbalance with a sensitivity of $0.001 \mathrm{mg}$ (Mettler XP6 Microbalance, Mettler Toledo, Hightstown, NJ, USA), each beam was allocated to a group based on similar baseline dry mass. Then, the beams were rehydrated in distilled water at $4{ }^{\circ} \mathrm{C}$ for $2 \mathrm{~h}$, placed in labeled polypropylene tubes for incubation ( $n=10$ /group).

The incubation was performed in $1 \mathrm{ml}$ of artificial saliva (AS, $5 \mathrm{mM}$ HEPES, $2.5 \mathrm{mM} \mathrm{CaCl}_{2} \cdot \mathrm{H}_{2} \mathrm{O}, 0.02 \mathrm{mM} \mathrm{ZnCl}_{2}$ ) with $\mathrm{CaF}_{2}$ in the $\mathrm{F}$ concentrations of $6,12,24,48,120,179,238 \mathrm{mM}$ at pH 7.4 for 1,7 or 21 days. The control group beams were incubated only in AS. Afterwards, all groups were incubated only in AS without any $\mathrm{F}$ content at $\mathrm{pH} 7.4$ for 6 months. Due to the low water solubility of $\mathrm{CaF}_{2}$, the incubation solution was prepared by heating up to $60^{\circ} \mathrm{C}$ in a beaker under constant stirring, and then cooled to room temperature. The F content of the solution was directly measured using a fluoride ion-selective electrode (DX219-F, Mettler Toledo, Urdorf, Switzerland). A shaking bath (OLS200, Grant Instruments, Cambridge, UK) was used for the incubation at 60 cycles $/ \mathrm{min}$ and at $37^{\circ} \mathrm{C}$ under constant $\mathrm{pH}$. At the end of each incubation period, the medium was stored at $-70{ }^{\circ} \mathrm{C}$ until further analysis of collagen degradation products.

\subsection{Total MMP activity}

A generic colorimetric MMP assay (Sensolyte Generic MMP assay; Anaspec, San Jose, CA, USA) was used to measure the total activity of dentin matrix-bound MMPs subjected to $\mathrm{CaF}_{2}$ (Altinci et al., 2016; Ozcan et al., 2015). Demineralized dentin beams (phosphoric acid 10\%) used as enzyme source were immersed in $300 \mu$ of chromogenic thiopeptide substrate and assay buffer for $60 \mathrm{~min}$ at $25^{\circ} \mathrm{C}$ ( $\mathrm{n}=10$ /group). Then, the beams were removed from the wells, and the absorbance values were measured at $412 \mathrm{~nm}$. Based on the similar baseline MMP activity, the beams were divided into groups ( $n=10 /$ group). At the end of each incubation period, the beams were rinsed with distilled water, and their total MMP activities were measured again. The results were calculated as a percentage of the untreated baseline level to determine the percent of inhibition or activation.

\subsection{Dry mass loss}

As an indirect indicator of dentin matrix degradation, the dry mass loss of the beams was measured at the end of each incubation period ( $n=10$ /group). For this purpose, the buffer salts were washed off in distilled water under constant stirring at $4{ }^{\circ} \mathrm{C}$ for $8 \mathrm{~h}$. Then, the beams were dried to a constant weight in the desiccator for $72 \mathrm{~h}$. After weighing the beam dry masses with the digital microbalance, they were rehydrated in distilled water at $4{ }^{\circ} \mathrm{C}$ for $2 \mathrm{~h}$, and taken to the next incubation period with a fresh incubation medium. The results were calculated based on the respective baseline dry masses, and expressed as the rate of dry mass loss.

\subsection{Hydroxyproline analysis}

Approximately 9.6 mass\% of type I collagen fibrils is constituted by an amino acid hydoxyproline (HYP). The measurement of HYP quantity in the incubation medium of dentin beams indicates the total liberated collagen by the activity of both MMPs and CCs (Tezvergil-Mutluay, Agee, Hoshika, Tay, \& Pashley, 2010). To hydrolyze the collagen fragments into amino acids, $400 \mu \mathrm{l}$ of incubation medium of dentin beams was mixed with $400 \mu \mathrm{HCl}$ to a final acid concentration of $6 \mathrm{~N}$ $\mathrm{HCl}$ in glass ampules (Wheaton, Millville, NJ, USA) ( $\mathrm{n}=10$ /group). The ampules were sealed using a flame sealer (Ampulmatic, Bioscience, Inc., Allentown, PA, USA), and incubated at $118^{\circ} \mathrm{C}$ for $18 \mathrm{~h}$. After cooling to room temperature, the content was dried in the desiccator connected to a $\mathrm{NaOH}$ pellet container to trap $\mathrm{HCl}$ vapor, and processed according to the hydroxyproline method described by Jamall, Finelli, and Que Hee, (1981). To each ampule, 50\% isopropanol in water $(1.2 \mathrm{ml})$, and Chloramine $\mathrm{T}$ solution with acetate citrate buffer $(0.2 \mathrm{ml})$ were pipetted. After $10 \mathrm{~min}$., Ehrlich's solution $(1 \mathrm{ml})$ prepared with 4 dimethylamineobenzaldehyde, $60 \%$ perchloric acid and $100 \%$ isopropanol was added. Following incubation at $50{ }^{\circ} \mathrm{C}$ for $90 \mathrm{~min}$., the liquids were transferred to the cuvettes, and the absorbances were read by a spectrophotometer (Model UV-A180, Shimadzu, Tokyo Japan) at $558 \mathrm{~nm}$. The results were calculated as $\mu \mathrm{g}$ of hydroxyproline $/ \mathrm{mg}$ of the dry mass of demineralized dentin before incubation.

\subsection{CTX analysis}

C-terminal crosslinked telopeptide of type I collagen (CTX) is produced by the catalytic activity of CCs. The CTX levels in the incubation medium of dentin beams can be regarded as an indicator of the CC activity in demineralized dentin matrix (Garnero et al., 2003; TezvergilMutluay et al., 2015). Therefore, the CTX levels of the aliquots (20 ul) were measured with specific assay kits for human serum CTX (Serum CrossLaps ELISA, Immunodiagnostic System, Farminton, UK) using a plate reader (Synergy HT, BioTek Instruments, Vermont, USA) $(n=10 /$ group). The absorbances were measured at $450 \mathrm{~nm}$ with $650 \mathrm{~nm}$ as reference. The experiments were performed in triplicate.

\subsection{Scanning electron microscopy and EDS analysis}

From each group, 5 representative beams were gold-sputtered (SC7620 Sputter Coater, Quorum, East Sussex, UK) after 21 days and 6 months incubation, and scanning electron microscopy (SEM) images were taken with a SEM device (Phenom-World, Eindhoven, The Netherlands) operating at $10 \mathrm{kV}$. The beams were fractured after kept in liquid nitrogen for $5 \mathrm{~min}$, and further examined for elemental composition with an EDS detector integrated to SEM device at $15 \mathrm{kV}$ with line scan function up to approximately $100 \mu \mathrm{m}$ in depth of the beams. 


\subsection{Gelatin zymography}

Gelatine zymography for the MMP-9 and MMP-2 activities in dentin was performed using dentin powder as enzyme source. For this purpose, coronal dentin pieces were obtained from approximately 100 sound molar after removing the roots, coronal enamel and intrapulpal dentin with high-speed burs under water cooling. Dentin pieces were placed into the metal containers of a cryomilling machine together with 2 metal balls. After the metal lids were tightened, the container was dipped into the liquid nitrogen for $5 \mathrm{~min}$, then placed to the machine, and shaken for $2.5 \mathrm{~min}$. The resultant fine mineralized dentin powder was collected in tubes, and stored at $-70^{\circ} \mathrm{C}$ until use.

Gelatine zymography was performed according to the protocol of Mazzoni et al. (2013). Demineralized (10\% phosphoric acid for $10 \mathrm{~min}$ ) dentin powder batches ( $200 \mathrm{mg} /$ group) were treated with $\mathrm{CaF}_{2}$ in the $\mathrm{F}$ concentrations of $6,12,24,48,120,179,238 \mathrm{mM}(100 \mu \mathrm{l})$ for $5 \mathrm{~min}$ at $4{ }^{\circ} \mathrm{C}$, centrifuged $(12.000 \mathrm{~g}, 20 \mathrm{~min})$, and the supernatants were discarded. Following washing with distilled water, the samples were suspended in extraction buffer containing $50 \mathrm{mM}$ Tris- $\mathrm{HCl} \mathrm{pH} 6$, containing $5 \mathrm{mM} \mathrm{CaCl}_{2}, 100 \mathrm{mM} \mathrm{NaCl}, 0.1 \%$ Triton X-100, $0.1 \%$ nonionic detergent P-40, $0.1 \mathrm{mM} \mathrm{ZnCl}_{2}, 0.02 \% \mathrm{NaN}_{3}$ for $24 \mathrm{~h}$ at $4{ }^{\circ} \mathrm{C}$, sonicated (for $10 \mathrm{~min}$, twice), and centrifuged $\left(12.000 \mathrm{~g}, 20 \mathrm{~min}\right.$ at $4^{\circ} \mathrm{C}$ ). The supernatants were collected, and concentrated $(10.000 \mathrm{~g}, 20 \mathrm{~min}$ at $4^{\circ} \mathrm{C}$ ) to $50 \mu \mathrm{l}$ total volume via Vivaspin centrifugal concentrator (10.000 kDa cut off; Vivaspin Sartorius Stedim Biotech, Goettingen, Germany). Total protein concentration of the dentin extracts was determined by Bradford assay. Then, the protein aliquots of $100 \mu \mathrm{g}$ were diluted (1/4 ratio) in Laemmli sample buffer. After the electrophoresis performed in $10 \%$ sodium dodecyl sulfate-polyacrylamide gel (SDSPAGE containing $1 \mathrm{mg} / \mathrm{ml}$ fluorescein-labeled gelatin), and washing in $2 \%$ Triton $\mathrm{X}-100$ for $1 \mathrm{~h}$, the gel was incubated in zymography activation buffer $\left(50 \mathrm{mmol} / \mathrm{L}\right.$ Tris- $\left.\mathrm{HCl}, 5 \mathrm{mmol} / \mathrm{L} \mathrm{CaCl}_{2}, \mathrm{pH} 7.4\right)$ for $48 \mathrm{~h}$. Prestained low-range molecular weight SDS-PAGE standards (Bio-Rad, Hercules, CA, USA) were used as molecular-weight markers. The gelatinase activity in the demineralized dentin powder was also analyzed. The results were monitored using a long-wave UV light scanner (ChemiDoc Universal Hood, Bio-Rad, Hercules, CA, USA). The entire experiment was performed in duplicate.

\subsection{Statistical analysis}

Data of total MMP activity, dry mass loss, HYP and CTX analyses were evaluated with Shapiro-Wilk and Brown-Forsythe test for normality and equal-variance assumptions, respectively. Since these parameters were satisfied, repeated measures ANOVA tests were applied based on 'pretreatment' as group variable, and 'timepoint' as the repeated factor. In case significant interactions were found, one-way ANOVA with Tukey HSD post hoc tests were performed. All statistical tests were performed using SPSS Statistics 23.0 software (IBM Corporation, Armonk, NY, USA) at $\mathrm{p}=.05$.

\section{Results}

The mean $( \pm S D)$ total MMP activity of dentin beams after each incubation period is shown in Fig. 1. After 1 day of incubation, there was a reduction in the MMP activity of $\mathrm{CaF}_{2}$ groups, which was only significant for F $238 \mathrm{mM}$ group ( $\mathrm{p}<.05$ ). After 7 days of incubation, there was a gradual decrease in the MMP activities of F groups, which were statistically significant for F 24, 179 and $238 \mathrm{mM}$. However, after 21 days of incubation, there were no significant differences between the MMP activities of $F$ groups and the control $(p>.05)$.

The mean $\left( \pm\right.$ SD) dry mass loss of the control and the $\mathrm{CaF}_{2}$ groups after 1, 7 and 21 days of incubation is presented in Fig. 2. Compared to the control, the dry mass loss of the F groups significantly decreased starting from the $24 \mathrm{mM}$ F group after 1 day, and $48 \mathrm{mM} \mathrm{F}$ after the 7 days of incubation. As seen in Fig. 3, in consistence with dry mass loss results, there were slight decreases in the CTX levels, which was statistically significant for $\mathrm{F} \geq 120 \mathrm{mM}$ groups after 21 days. However, no significant difference was detected between the HYP levels of the control and $\mathrm{F}$ groups at all timepoints $(\mathrm{p}>.05)$.

The total MMP activity, dry mass loss, hydroxyproline and CTX assay results of the control and $\mathrm{CaF}_{2}$ groups incubated for 6 months in AS are shown in Fig. 4. The MMP activity ranged between $45-60 \%$ among the groups with no significant difference $(p>.05)$. Likewise, there were no significant differences between the dry mass loss and the CTX levels of $\mathrm{CaF}_{2}$ groups and the control ( $\left.\mathrm{p}>.05\right)$. The HYP levels of F 24 and $238 \mathrm{mM}$ were significantly higher than the control ( $<<.05)$.

The SEM-EDS images of the representative beams after the 21 days and 6 months of incubation are shown in Fig. 5. As confirmed by EDS, $\mathrm{CaF}_{2}$-like minerals were observed on dentin beams with increasing density in correlation with the increasing $\mathrm{CaF}_{2}$ concentrations. After 6 months incubation, the precipitations were still dense over the beams. Inside the dentin, $\mathrm{F}$ ion infiltration was confirmed to the approximately $100 \mu \mathrm{m}$ in depth.

Fig. 6 shows the gelatin zymography results of demineralized dentin powder samples treated with increasing concentrations of $\mathrm{CaF}_{2}$ with $\mathrm{F}$ 6-238 mM. In the protein extract of demineralized dentin powder the bands detected at $95 \mathrm{kDa}$ and $68-72 \mathrm{kDa}$, corresponding to the molecular weights of proMMP-9, and active and proforms of MMP-2, respectively. The bands showing MMP-2 and -9 activities in $\mathrm{CaF}_{2}$ groups were remarkably noticeable, indicating that there was no inhibition.

\section{Discussion}

This study investigated the effect of $\mathrm{CaF}_{2}$ on the catalytic activity of dentin matrix-bound MMPs and CCs for the prevention of demineralized dentin matrix degradation. As direct indicators of the MMP activity, total MMP activity assay and gelatin zymography were performed. Despite the gradual decrease in the total MMP activity after 7 and 21 days of incubation, there was no inhibition in the MMP-2 and MMP-9 activities according to the zymography. Hence, the indirect indicators of the enzymatic degradation in dentin organic matrix were analyzed involving the beam mass loss, and CTX and HYP assays. Up to 21 days of incubation, mass loss and CTX results consistently indicated that $\mathrm{CaF}_{2}$ could be effective in the inhibition of CCs. However, there was no decrease in the HYP levels of $\mathrm{CaF}_{2}$ groups compared to control at all incubation periods. Furthermore, there was no CC inhibition according to the CTX results after 6 months of incubation. Therefore, it was concluded that $\mathrm{CaF}_{2}$ does not prevent the degradation of demineralized dentin organic matrices due to MMPs or CCs. Hence, the tested null hypothesis was accepted.

It has been previously suggested that salivary MMPs and dentin matrix-bound CCs can be inhibited by the high levels of NaF and KF (Altinci et al., 2016; Kato et al., 2014; Mei et al., 2014). Moreover, KF was effective in the long-term inhibition of CCs (Altinci et al., 2017). These results have been attributed to highly electronegative $\mathrm{F}$ ions, binding to the zinc and calcium in the enzyme structure, thereby blocking the catalytic domain, or causing conformational changes in the enzyme morphology. In the present study, $\mathrm{CaF}_{2}$ was used as fluoride source, however similar inhibitory effects could not been obtained. One reason might be the low water solubility of $\mathrm{CaF}_{2}$ as a difluoride compound compared to the highly water-soluble monofluorides, $\mathrm{NaF}$ and $\mathrm{KF}$. Another reason might be the substrate preference of $\mathrm{F}$ ions. Assuming that $\mathrm{F}$ ions primarily prefer binding to $\mathrm{Ca}^{2+}$ ions, the interaction of $\mathrm{F}$ compounds with dentin matrix-bound MMPs and CCs can be explained. In case of no free $\mathrm{Ca}^{2+}$ ions in the media, $\mathrm{F}$ ions can bind to structural $\mathrm{Ca}^{2+}$ and $\mathrm{Zn}^{2+}$ ions of MMPs, which clarifies the inhibition of salivary MMPs with high F concentrations (Kato et al., 2014). On the other hand, there were $\mathrm{Ca}^{2+}$ ions in artificial saliva used in this study, readily available for $\mathrm{F}$ binding. After reacting with these $\mathrm{Ca}^{2+}$ ions, the remaining $\mathrm{F}$ ions can bind to the enzymes. At this point, it can be also suggested that the required $\mathrm{F}$ concentration could be lower for 
600

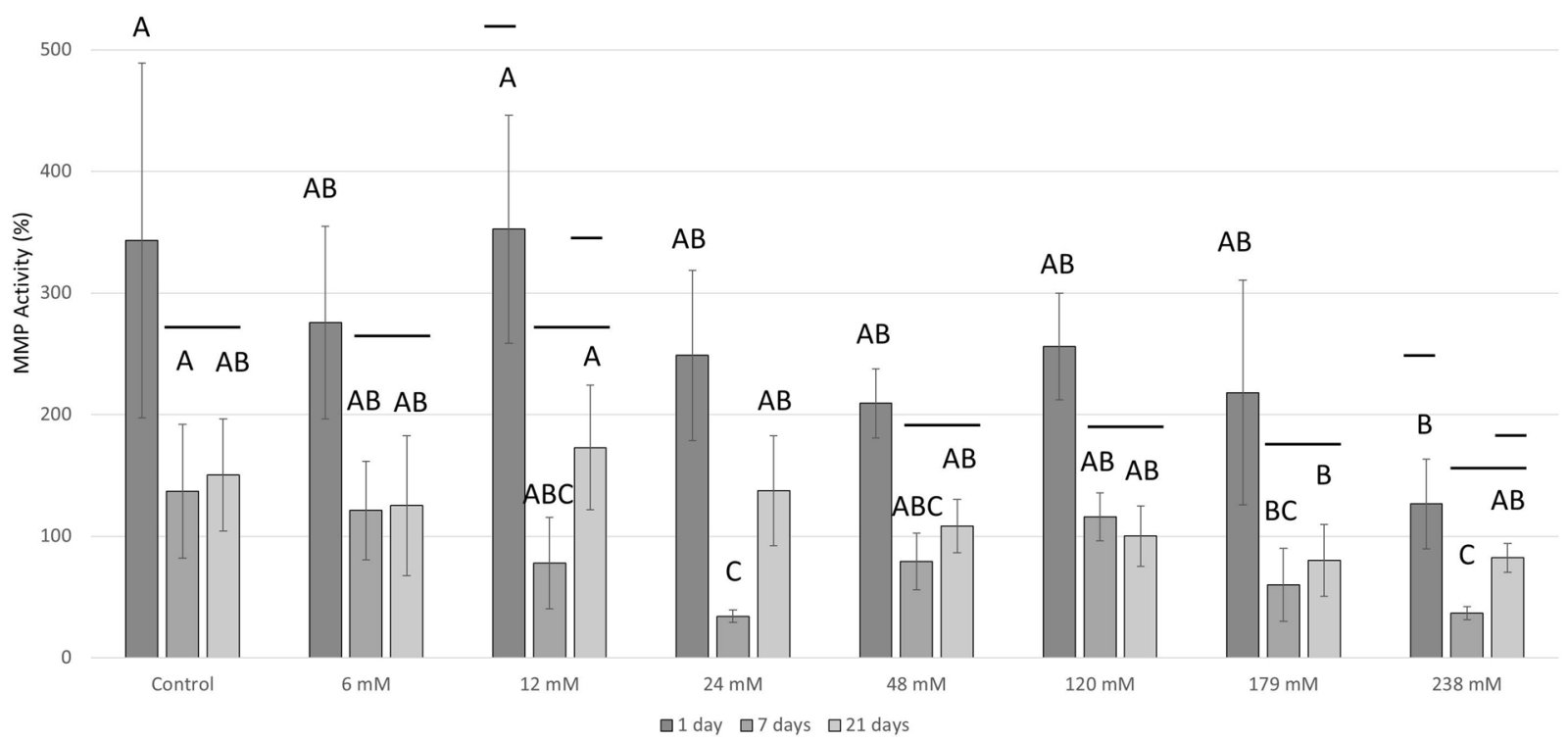

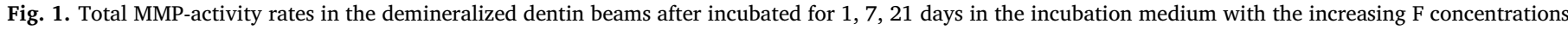

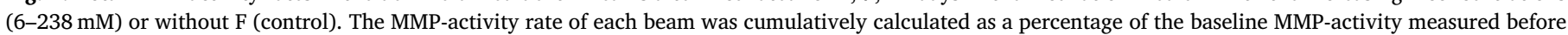

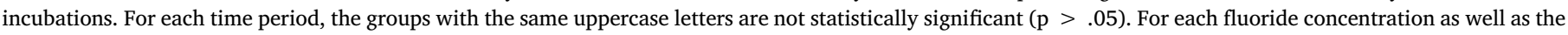
control, time period columns connected by a solid black bar are not statistically significant $(\mathrm{p}>.05)$.

cathepsin inhibition than MMPs since dentin matrix-bound CCs were significantly inhibited by $\mathrm{NaF}$ and KF (Altinci et al., 2016, 2017). Higher $\mathrm{F}$ concentrations also resulted in denser mineral precipitations on dentin, possibly because the initial precipitations behaved as nuclei for crystal growth (Lussi et al., 2012). Therefore, MMP inhibition could not been observed in demineralized dentin with high $\mathrm{F}$ concentrations either.
$\mathrm{CaF}_{2}$-like minerals can form on dentin depending on the solubilization of $\mathrm{Ca}^{2+}$ ions from tooth surface, $\mathrm{F}$ exposure duration, $\mathrm{F}$ concentration and the $\mathrm{pH}$ of the F solution (Ogaard, 2001). Present study was implemented at $\mathrm{pH} 7.4$ considered the optimum $\mathrm{pH}$ range for the activity of MMPs and the structural stability of collagen fibrils. On the other hand, CCs demonstrate higher catalytic activity at $\mathrm{pH} 5.5$ (Tezvergil-Mutluay et al., 2015). If the same study was performed at $\mathrm{pH}$

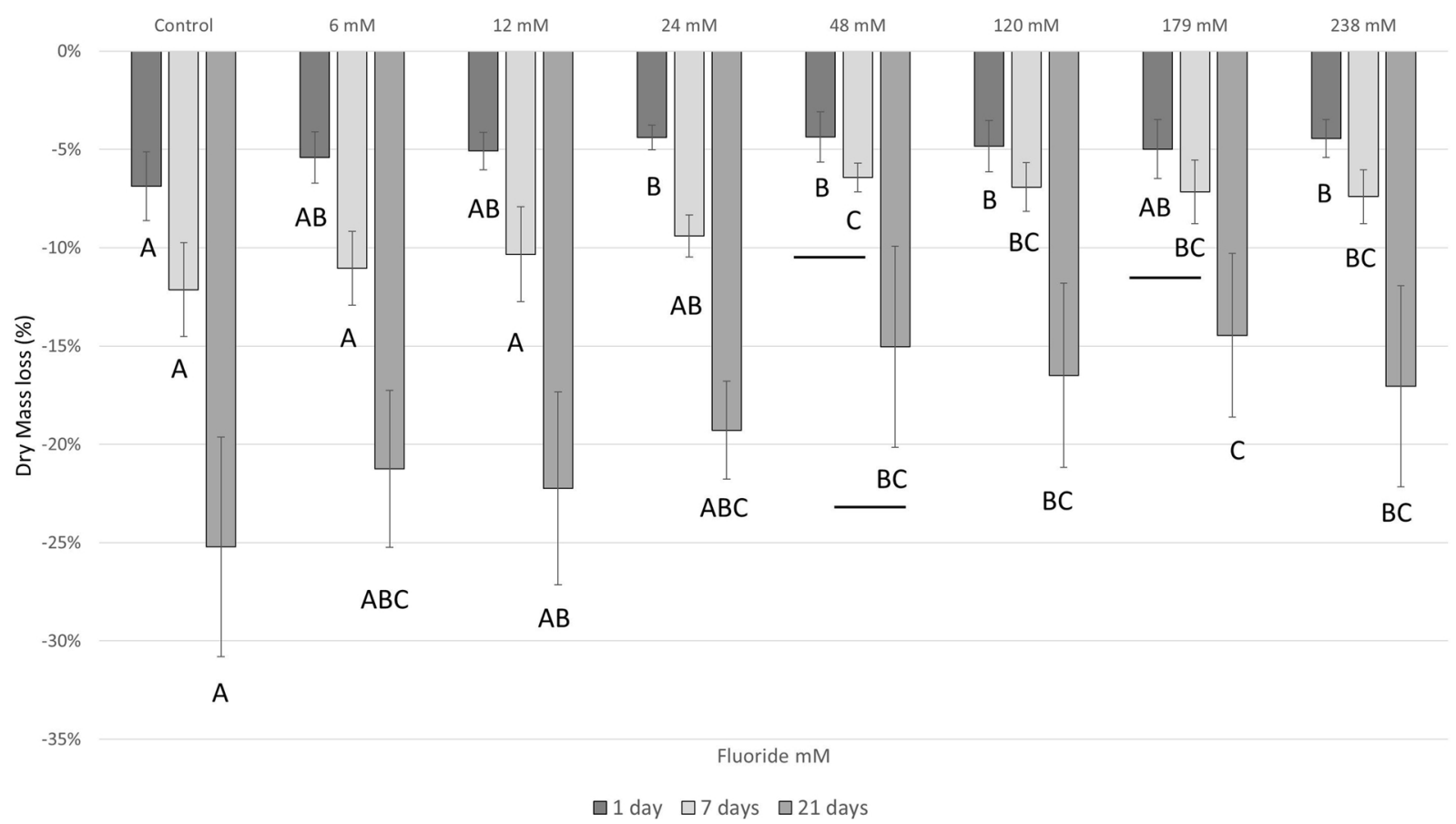

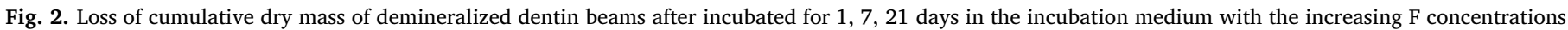

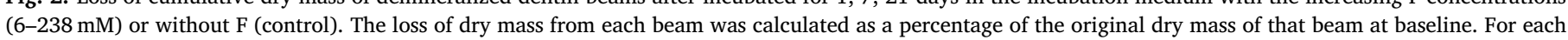

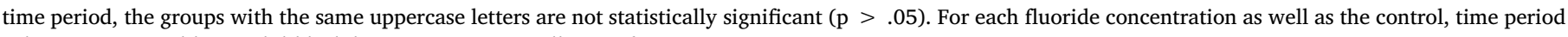
columns connected by a solid black bar are not statistically significant $(\mathrm{p}>$.05). 

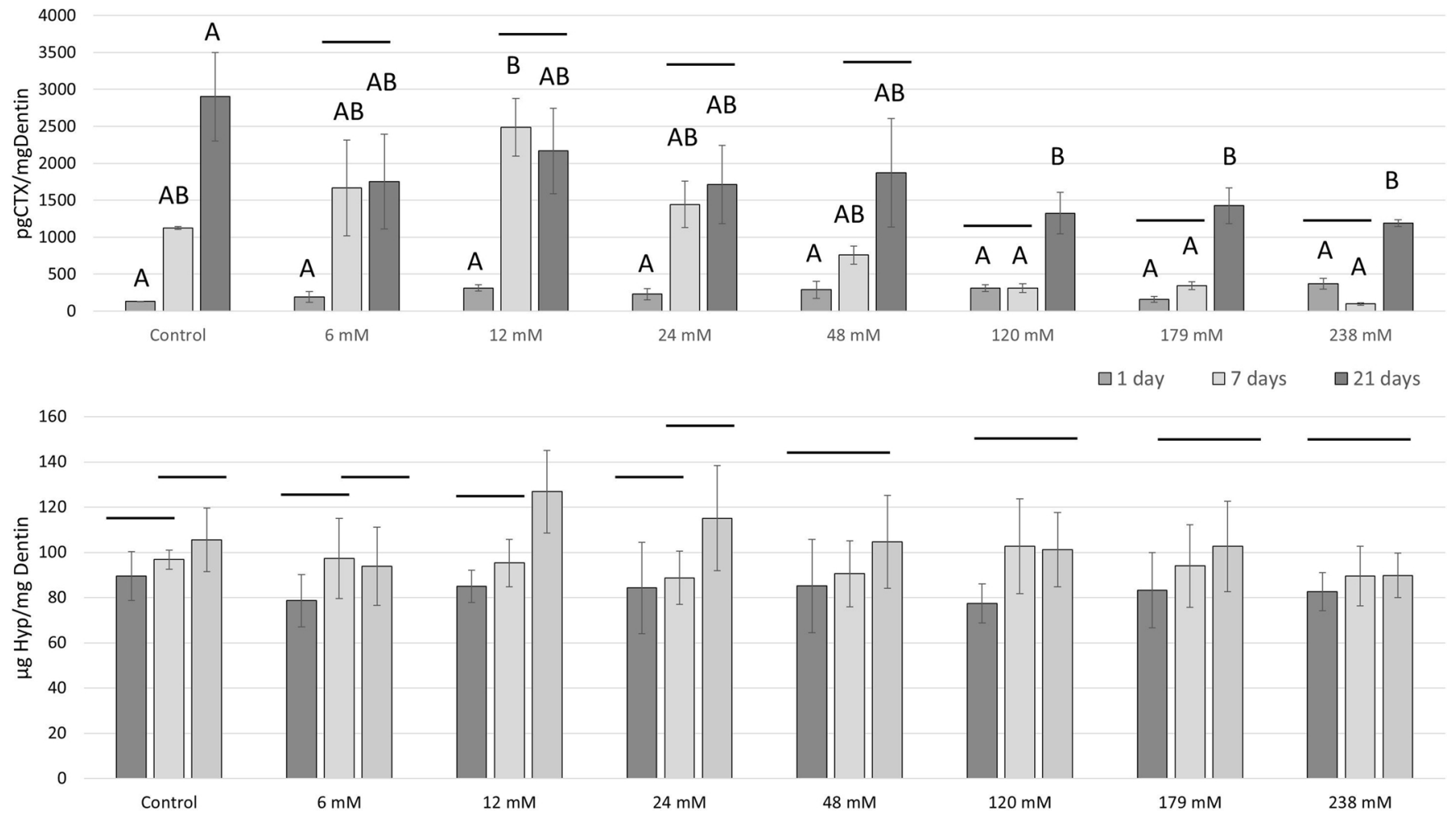

Fig. 3. Bar charts comparing the liberated mean CTX and hydroxyproline levels with standard deviations from demineralized dentin beams after incubated for 1,7 , 21 days in the incubation medium with the increasing $\mathrm{F}$ concentrations $(6-238 \mathrm{mM})$ or without $\mathrm{F}$ (control). For each time period, the groups with the same uppercase letters are not statistically significant $(\mathrm{p}>.05)$. For each fluoride concentration as well as the control, time period columns connected by a solid black bar are not statistically significant $(\mathrm{p}>.05)$.
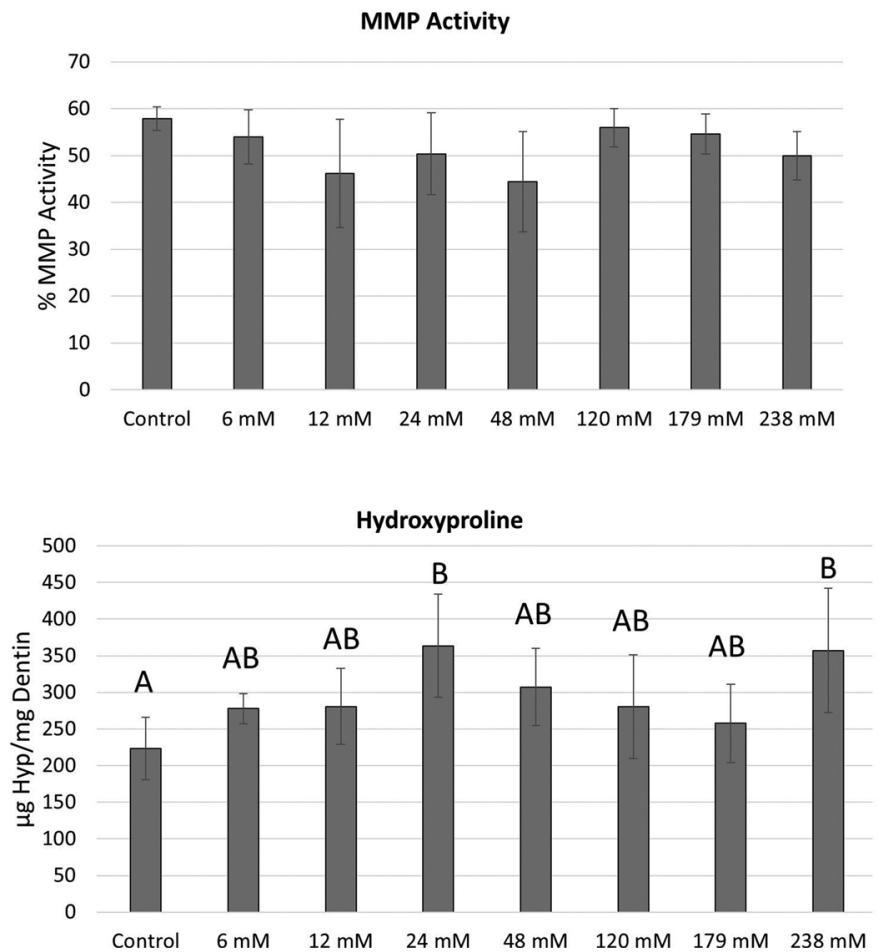

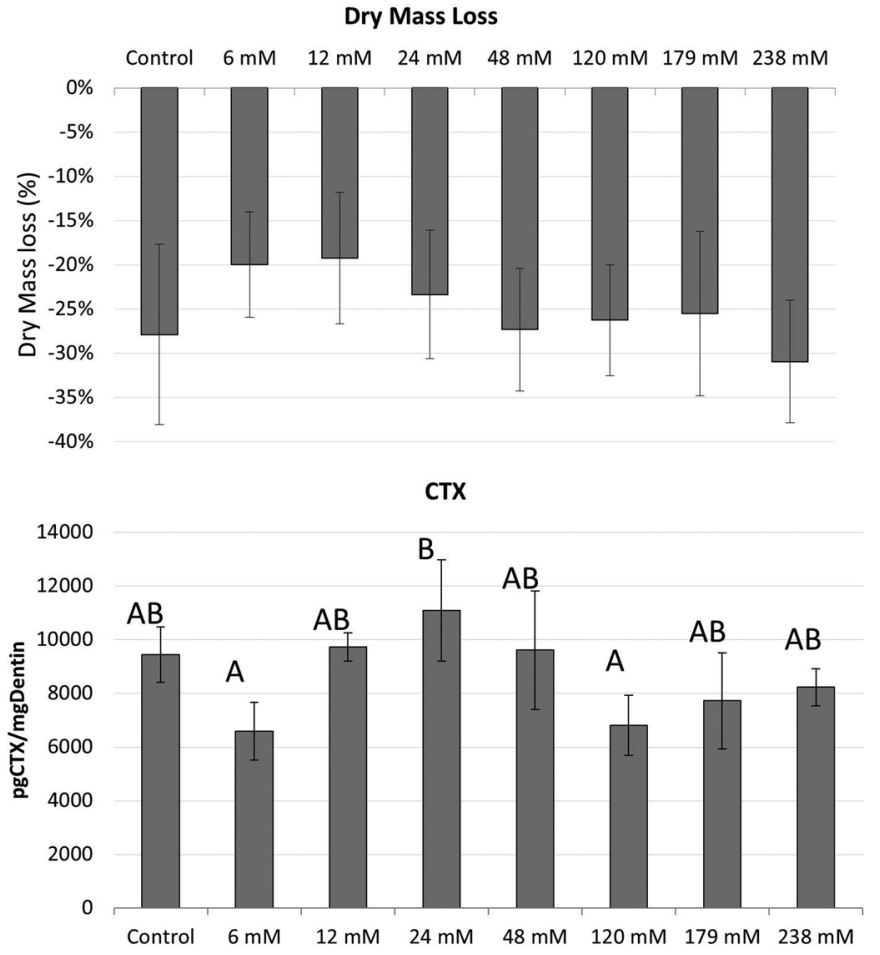

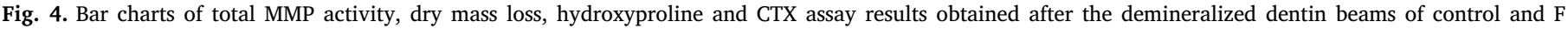

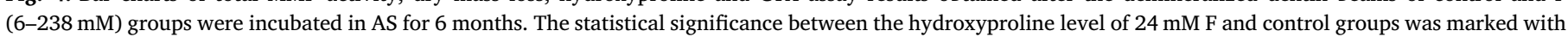
an asterisk $\left.{ }^{*}\right)(\mathrm{p}<.05)$. 

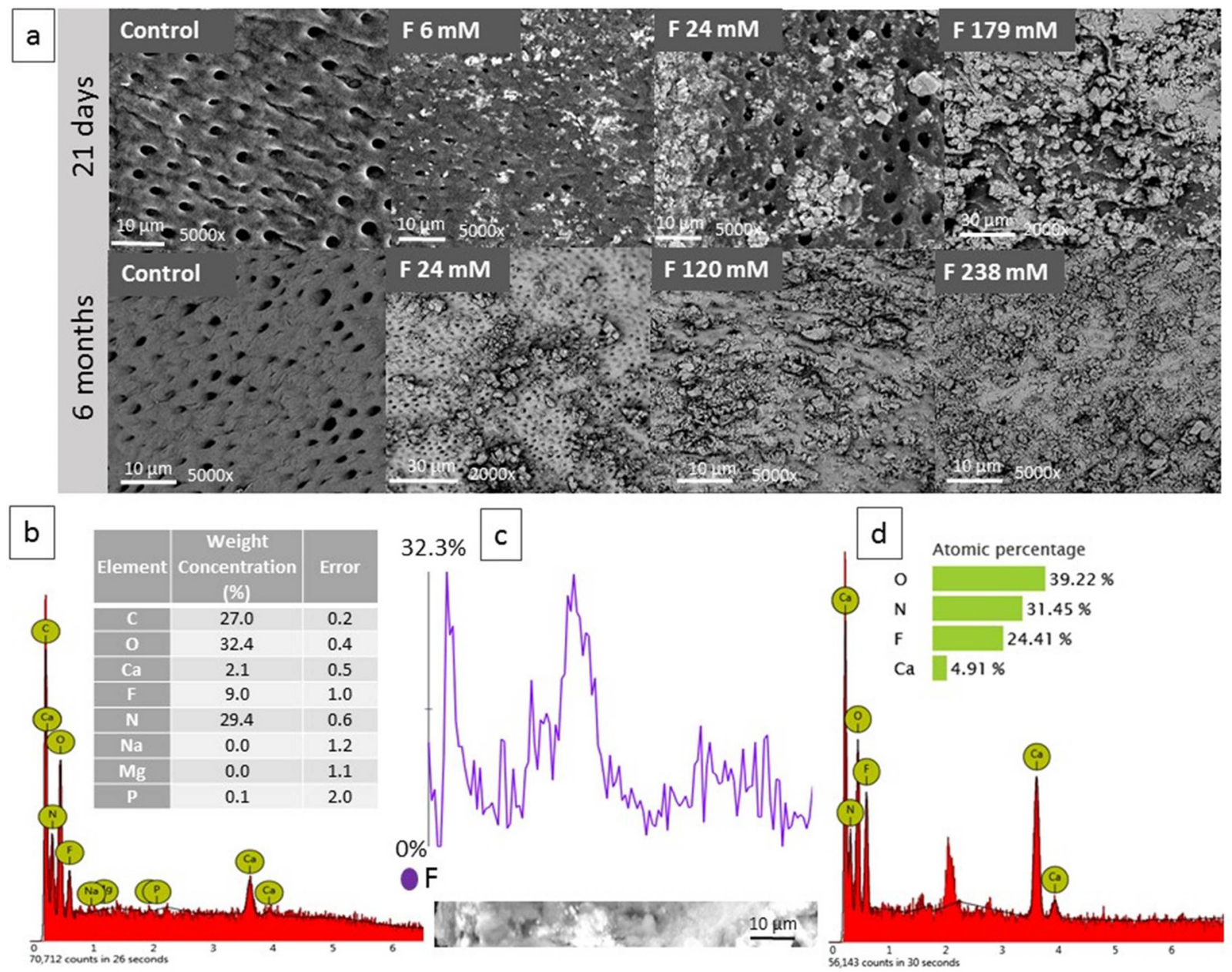

Fig. 5. Representative SEM-EDS images of the surface of completely demineralized dentin beams incubated for 21 days and 6 months at increasingly higher medium $\mathrm{F}$ concentrations. $\mathrm{CaF}_{2}$-like precipitations might be dense enough to prevent the elution of telopeptides to the incubation medium, and remained mostly undissolved after the beams were incubated in artificial saliva for 6 months (Fig. 5a). EDS analysis of the dentin beam incubated at F $120 \mathrm{mM}$ detected the fluoride level at the dentin surface as $9 \mathrm{wt} \%$ (Fig. 5b). Y-axis of Fig. $5 \mathrm{c}$ represents the specimen surface, and demonstrates stabile fluoride penetration into the beam as approximately $10 \%$ after $21 \mathrm{~d}$ incubation. The presence of fluoride ions was confirmed on the dentin beam surfaces after 6-month incubation (Fig. 5d).

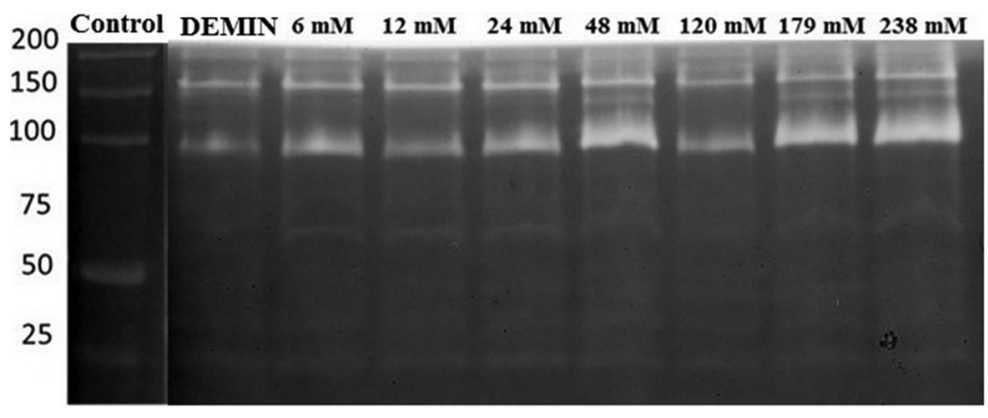

Fig. 6. Gelatin zymography of dentin protein extracted from demineralized dentin powder. Column 1: Control; proteins extracted from dentin powder demineralized with $10 \%$ phosMMP 9 phoric acid, showing the presence of MMP-2 and MMP-9; Column 2-8: demineralized dentin powder treated with increasing concentrations of $\mathrm{F}(6-238 \mathrm{mM})$ demonstrating the MMP 2 presence of MMP-2 and MMP-9.

5.5 , it could be expected that the mineral precipitation on dentin would be much higher compared to the neutral $\mathrm{pH}$. Moreover, $\mathrm{CaF}_{2}$-like precipitations have been observed in the previous studies executed with the similar study design (Altinci et al., 2016, 2017). It was previously suggested that these precipitations prevented the release of degradation products to the incubation medium, which could be the reason of lower CTX levels detected in $\mathrm{CaF}_{2}$ groups after the 7 and 21 days of incubation. However, after 6 months, the CTX levels were similar among all groups, probably due to the dissolution of the precipitations allowing the transition of the nano-sized fragments to the incubation medium.

MMPs require $\mathrm{Ca}^{2+}$ ions to maintain their structural integrity, and for the catalytic functions (Tezvergil-Mutluay, Agee, Hoshika, Carrilho et al., 2010). In this study, $\mathrm{Ca}^{2+}$ level in the incubation medium was also increased in correlation with the increasing $\mathrm{CaF}_{2}$ concentrations. However, the relation between $\mathrm{Ca}^{2+}$ ions and the enzymatic activity in demineralized dentin matrix cannot be evaluated with the current study design, which was also not within the scope of the study.

\section{Conclusion}

Within the limitations of this study, it was concluded that $\mathrm{CaF}_{2}$ does not prevent the degradation of demineralized dentin matrices by matrix metalloproteinases and cysteine cathepsins, possibly due to the formation of $\mathrm{CaF}_{2}$-like minerals on dentin preventing the interaction of $\mathrm{F}$ 
ions with the enzymes.

\section{Author contributions}

P. Altinci, M. Mutluay, L. Tjäderhane and A. Tezvergil-Mutluay contributed to the research design. P. Altinci was responsible from the laboratory testing and data gathering. P. Altinci, M. Mutluay, L. Tjäderhane and A. Tezvergil-Mutluay analyzed the data. P. Altinci drafted the manuscript. All authors participated in the editing and final preparation of the manuscript.

\section{Acknowledgements}

This study was funded by the grant \#296653 from the Academy of Finland to AT-M (PI) and EVO funding \#13140 of Turku University Hospital to AT-M (PI). The funders had no role in study design, data collection and analysis, decision to publish, or preparation of the manuscript. The authors do not have a financial interest in products, equipment, and companies cited in the manuscript. The authors thank the staff of the Helsinki Finnish Student Health Service (FSHS) and Turku Student Health Service for collecting the teeth for the experiments.

The authors would like to thank to the biomedical laboratory technician Katja Sampalahti for performing CTX assays, to Docent Dr. Roda Seseogullari-Dirihan for her contributions to the total MMP activity assays, and to Kaveh Nik Jamal, MSc for performing SEM-EDS examinations in this study.

\section{References}

Altinci, P., Mutluay, M., Seseogullari-Dirihan, R., Pashley, D., Tjäderhane, L., \& TezvergilMutluay, A. (2016). NaF inhibits matrixbound cathepsin-mediated dentin matrix degradation. Caries Research, 50(2), 124-132. https://doi.org/10.1159/000444222.

Altinci, P., Mutluay, M., Tjäderhane, L., \& Tezvergil-Mutluay, A. (2017). Potassium fluoride inhibits the catalytic activity of dentin-bound cysteine cathepsins. Journal of Dental Research, 96(Spec Iss A) 1794.

Buzalaf, M. A., Pessan, J. P., Honório, H. M., \& ten Cate, J. M. (2011). Mechanisms of action of fluoride for caries control. Monographs in Oral Science, 22, 97-114. https:// doi.org/10.1159/000325151.

Buzalaf, M. A., Charone, S., \& Tjäderhane, L. (2015). Role of host-derived proteinases in dentine caries and erosion. Caries Research, 49(Suppl. 1), 30-37. https://doi.org/10. 1159/000380885.

Chaussain, C., Boukpessi, T., Khaddam, M., Tjaderhane, L., George, A., \& Menashi, S. (2013). Dentin matrix degradation by host matrix metalloproteinases: Inhibition and clinical perspectives toward regeneration. Frontiers in Physiology, 4, 308. https://doi. org/10.3389/fphys.2013.00308.

Chaussain-Miller, C., Fioretti, F., Goldberg, M., \& Menashi, S. (2006). The role of matrix metalloproteinases (MMPs) in human caries. Journal of Dental Research, 85(1), 22-32. https://doi.org/10.1177/154405910608500104.

Cheng, L., Weir, M. D., Xu, H. H., Kraigsley, A. M., Lin, N. J., Lin-Gibson, S., et al. (2012). Antibacterial and physical properties of calcium-phosphate and calcium-fluoride nanocomposites with chlorhexidine. Dental Materials, 28(5), 573-583. https://doi. org/10.1016/j.dental.2012.01.006.

Frassetto, A., Breschi, L., Turco, G., Marchesi, G., Di Lenarda, R., Tay, F. R., et al. (2016). Mechanisms of degradation of the hybrid layer in adhesive dentistry and therapeutic agents to improve bond durability-A literature review. Dental Materials, 32(2), e41-53. https://doi.org/10.1016/j.dental.2015.11.007.

Garnero, P., Ferreras, M., Karsdal, M. A., Nicamhlaoibh, R., Risteli, J., Borel, O., et al. (2003). The type I collagen fragments ICTP and CTX reveal distinct enzymatic pathways of bone collagen degradation. Journal of Bone Mineral Research, 18(5),
859-867. https://doi.org/10.1359/jbmr.2003.18.5.859.

Jamall, I. S., Finelli, V. N., \& Que Hee, S. S. (1981). A simple method to determine nanogram levels of 4-hydroxyproline in biological tissues. Analytical Biochemistry, 112(1), 70-75. https://doi.org/10.1016/0003-2697(81)90261-X.

Kato, M. T., Bolanho, A., Zarella, B. L., Salo, T., Tjäderhane, L., \& Buzalaf, M. A. (2014). Sodium fluoride inhibits MMP-2 and MMP-9. Journal of Dental Research, 93(1), 74-77. https://doi.org/10.1177/0022034513511820.

Lussi, A., Hellwig, E., \& Klimek, J. (2012). Fluorides - Mode of action and recommendations for use. Schweizer Monatsschrift für Zahnmedizin, 122(11), 1030-1042.

Mazzoni, A., Scaffa, P., Carrilho, M., Tjäderhane, L., Di Lenarda, R., Polimeni, A., et al. (2013). Effects of etch-and-rinse and self-etch adhesives on dentin MMP-2 and MMP9. Journal of Dental Research, 92(1), 82-86. https://doi.org/10.1177/ 0022034512467034.

Mazzoni, A., Tjäderhane, L., Checchi, V., Di Lenarda, R., Salo, T., Tay, F. R., et al. (2015). Role of dentin MMPs in caries progression and bond stability. Journal of Dental Research, 94(2), 241-251. https://doi.org/10.1177/0022034514562833.

Mei, M. L., Ito, L., Cao, Y., Li, Q. L., Chu, C. H., \& Lo, E. C. (2014). The inhibitory effects of silver diamine fluorides on cysteine cathepsins. Journal of Dentistry, 42(3), 329-335. https://doi.org/10.1016/j.jdent.2013.11.018.

Ogaard, B. (2001). $\mathrm{CaF}(2)$ formation: cariostatic properties and factors of enhancing the effect. Caries Research, 35(Suppl. 1), 40-44. https://doi.org/10.1159/000049109.

Ozcan, S., Seseogullari-Dirihan, R., Uctasli, M., Tay, F. R., Pashley, D. H., \& TezvergilMutluay, A. (2015). Effect of polyacrylic acid on dentin protease activities. Dental Material, 31(8), 901-906. https://doi.org/10.1016/j.dental.2015.04.018.

ten Cate, J. M. (2013). Contemporary perspective on the use of fluoride products in caries prevention. British Dental Journal, 214(4), 161-167. https://doi.org/10.1038/sj.bdj. 2013.162.

Tezvergil-Mutluay, A., Agee, K. A., Mazzoni, A., Carvalho, R. M., Carrilho, M., Tersariol, I. L., et al. (2015). Can quaternary ammonium methacrylates inhibit matrix MMPs and cathepsins? Dental Materials, 31(2), e25-32. https://doi.org/10.1016/j.dental.2014. 10.006 .

Tezvergil-Mutluay, A., Agee, K. A., Hoshika, T., Carrilho, M., Breschi, L., Tjäderhane, L., et al. (2010). The requirement of zinc and calcium ions for functional MMP activity in demineralized dentin matrices. Dental Materials, 26(11), 1059-1067. https://doi.org/ 10.1016/j.dental.2010.07.006.

Tezvergil-Mutluay, A., Agee, K. A., Hoshika, T., Tay, F. R., \& Pashley, D. H. (2010). The inhibitory effect of polyvinylphosphonic acid on functional matrix metalloproteinase activities in human demineralized dentin. Acta Biomaterials, 6(10), 4136-4142. https://doi.org/10.1016/j.actbio.2010.05.017.

Tjäderhane, L. (2015). Dentin bonding: Can we make it last? Operative Dentistry, 40(1), 4-18. https://doi.org/10.2341/14-095-BL.

Tjäderhane, L., Larjava, H., Sorsa, T., Uitto, V. J., Larmas, M., \& Salo, T. (1998). The activation and function of host matrix metalloproteinases in dentin matrix breakdown in caries lesions. Journal of Dental Research, 77(8), 1622-1629. https://doi.org/ 10.1177/00220345980770081001.

Tjäderhane, L., Buzalaf, M. A. R., Carrilho, M., \& Chaussain, C. (2015). Matrix metalloproteinases and other matrix proteinases in relation to cariology: The era of "Dentin degradomics". Caries Research, 49(3), 193-208. https://doi.org/10.1159/ 000363582 .

Tjäderhane, L., Nascimento, F. D., Breschi, L., Mazzoni, A., Tersariol, I. L., Geraldeli, S., et al. (2013a). Optimizing dentin bond durability: Control of collagen degradation by matrix metalloproteinases and cysteine cathepsins. Dental Materials, 29(1), 116-135. https://doi.org/10.1016/j.dental.2012.08.004.

Tjäderhane, L., Nascimento, F. D., Breschi, L., Mazzoni, A., Tersariol, I. L., Geraldeli, S., et al. (2013b). Strategies to prevent hydrolytic degradation of the hybrid layer-A review. Dental Materials, 29(1), 999-1011. https://doi.org/10.1016/j.dental.2012. 08.004.

Weir, M. D., Moreau, J. L., Levine, E. D., Strassler, H. E., Chow, L. C., \& Xu, H. H. (2012) Nanocomposite containing CaF(2) nanoparticles: Thermal cycling, wear and longterm water-aging. Dental Materials, 28(6), 642-652. https://doi.org/10.1016/j. dental.2012.02.007.

Xu, H. H., Moreau, J. L., Sun, L., \& Chow, L. C. (2010). Novel CaF(2) nanocomposite with high strength and fluoride ion release. Journal of Dental Research, 89(7), 739-745. https://doi.org/10.1177/0022034510364490.

Xu, H. H., Weir, M. D., Sun, L., Moreau, J. L., Takagi, S., Chow, L. C., et al. (2010). Strong nanocomposites with $\mathrm{Ca}, \mathrm{PO}(4)$, and $\mathrm{F}$ release for caries inhibition. Journal of Dental Research, 89(1), 19-28. https://doi.org/10.1177/0022034509351969. 